
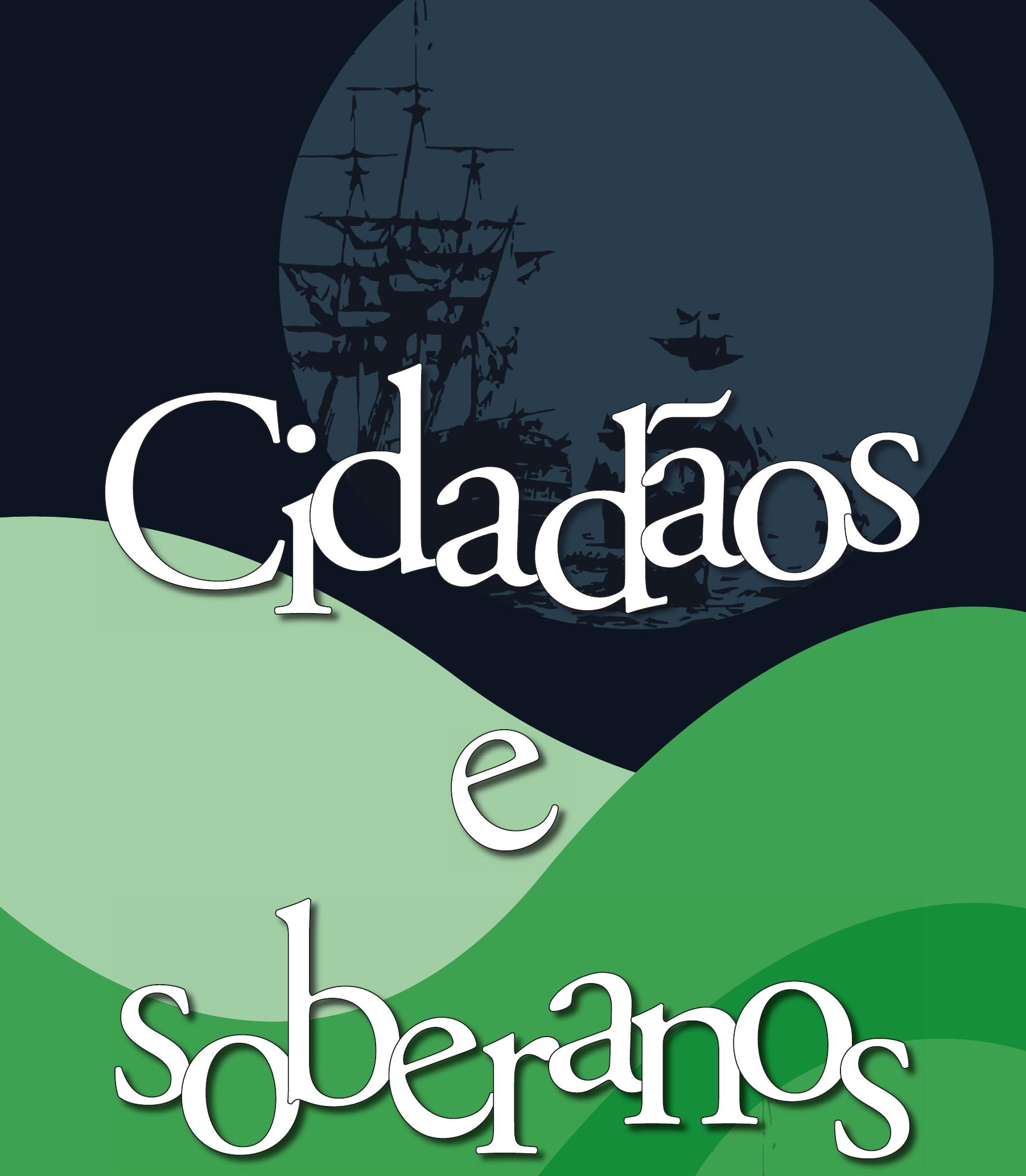


\section{A chegada da corte portuguesa na ótica norte-americana}

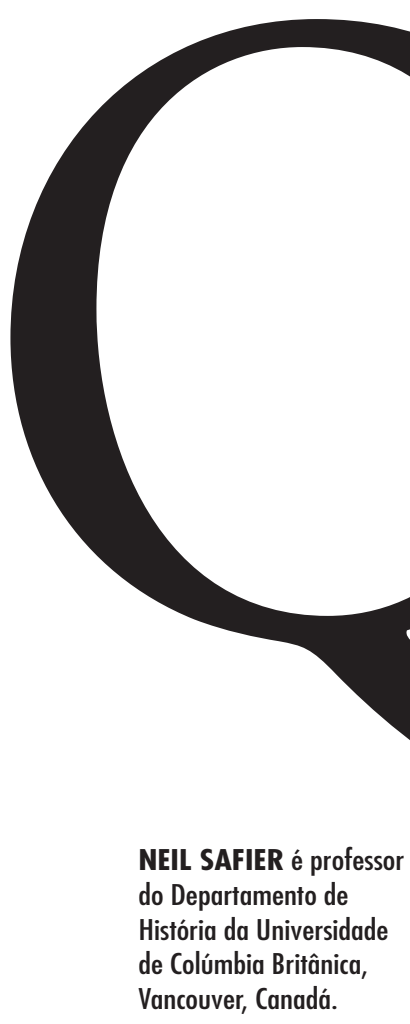

Hipólito da Costa, "Diário de Minha Viajem para Filadélfia 1798-1799", MSS, Biblioteca Pública de Évora, 11 /dez/ 1798.

2 Idem, 30/abr./1799.
NEIL SAFIER

Gostaria de agradecer a Maria Leal (Biblioteca Oliveira Lima, Washington, DC) e a Íris Kantor (USP) pela ajuda inestimável na execução desta pesquisa e na elaboração deste artigo.

uando Hipólito da Costa chegou à recém-batizada capital norte-americana no final de 1798 , o que mais capturou sua atenção foram os jornais e periódicos. Pisando nas docas da Filadélfia, no frio de uma manhã de dezembro, o jovem luso-brasileiro ficou maravilhado ao ver os anúncios impressos pendurados livremente nas paredes da casa de correios. Impressionaram-no os "muitos editais impressos para coisa [sic] de bagatela" e ele reconheceu que, "como a imprensa é livre, tudo se imprime para maior comodidade" ${ }^{1}$. Durante a sua estadia de quase dois anos na América do Norte, ele assinou a Gazette of the United States, a Aurora, e leu outros jornais e revistas, tais como o Medical Repository, especializado em questões de medicina e saúde pública, publicado em Nova York. Mas não era só para fazer a vida confortável que os documentos impressos eram amplamente difundidos. A imprensa também tinha um papel fundamental no processo político da jovem nação, e Hipólito da Costa destacou que os "diferentes pamphlets [sic] impressos se espalhavam a [ponto de] deteriorar o caráter daquelas pessoas que eram propostas para eleição"2. Acrescentou ainda outras observações sobre a participação de cidadãos comuns nesse processo e, sobretudo, o fato de que "havia em vários cafés, ou botequins, homens com caixas para receber votos". Com essas observações, demonstrou a forte conexão entre a imprensa livre e o compromisso dos cidadãos com o processo eleitoral, sugerindo que essa prática política era digna daquela celebrada república que tinha cortado os laços com a mãe-pátria havia somente duas décadas. 
Diferente dos republicanos norte-americanos, cuja influência se sentia profundamente na Filadélfia de finais do Setecentos, Hipólito da Costa não era a favor da separação entre sua terra natal - o Brasil - e a sede do Império português. Contudo, suas experiências na jovem federação dos Estados Unidos e na Inglaterra, onde passou quase duas décadas após a sua fuga inesperada de Portugal em 1805, marcaram-no de maneira decisiva, sobretudo pelo contato com sociedades que cultivavam a liberdade de expressão e a livre circulação de idéias. Foi o ministro português Dom Rodrigo de Sousa Coutinho que enviou Hipólito em missão oficial à república norte-americana com o objetivo de procurar informações precisas sobre a situação agrícola do país, fazer o inventário de espécies e identificar obras que pudessem melhorar a condição econômica e política em Portugal e nas suas colônias, especialmente no Brasil. Conhecido por editar o Correio Braziliense, jornal político que publicou durante o exílio em Londres entre 1808 e 1822, Hipólito da Costa também foi um ator importante nesse momento inicial das relações diplomáticas entre os Estados Unidos e o que viria a ser o Brasil, um relacionamento que começou justamente nos anos que precederam a chegada do jovem luso-brasileiro às margens geladas do Rio Delaware. Mais tarde, chegaria aos Estados Unidos o embaixador e botânico Corrêa da Serra, cuja amizade com Thomas Jefferson e outras figuras importantes da política norte-americana -inclusive um diplomata e erudito chamado Henry Marie Brackenridge - lhe atribuiria o apelido de o "Franklin de Portugal" com direito a uma sala na residência jeffersoniana em Monticello (Virgínia) em sua homenagem $^{3}$. Mesmo antes da ida do abade Corrêa da Serra, porém, o interesse pelos Estados Unidos já tinha crescido na ótica portuguesa,

3 Edward Corrêa da Serra a Vaughan, 1- de julho de 1823 citando em "The Abbé Correa in America, 1812-1820: The Contributions of the Diplomat and Natural Philosopher to the Foundations of Our $\mathrm{Na}$ tional Life", in Transactions of the American Philosophical Society, New Series, vol. 45, no 2,1955, p. 189 e através da viagem de Hipólito da Costa podemos entender o início dessas relações bilaterais que cresceriam ao longo de dois séculos até os nossos dias.

No momento em que Hipólito visitou os Estados Unidos no final do século XVIII, o Brasil ainda era colônia da Coroa portugue- sa, e figuras como Dom Rodrigo tentavam diminuir as distâncias que separavam os colonos da monarquia por intermédio de indivíduos como Hipólito. Educar jovens brasileiros em Coimbra e mandá-los para os quatro cantos do mundo era parte integrante dessa estratégia. Em poucos anos, porém, como bem se sabe, o Brasil se transformaria em metrópole, o Rio de Janeiro se tornaria capital de um vasto império, e em 1818 o príncipe regente seria aclamado rei de Portugal e do Brasil em terras americanas. Esse acontecimento inédito na história das Américas teve um impacto particular na primeira república do hemisfério, e a chegada da corte foi objeto de curiosidade mas também alvo de críticas pelos representantes diplomáticos dos Estados Unidos instalados no Rio de Janeiro. Como, então, foi percebida nos Estados Unidos essa transformação do Brasil de colônia em metrópole? Como a jovem república reagiu às notícias de uma monarquia nas Américas, tendo só recentemente conseguido se livrar das garras do monarca britânico? Sem pretender ver nisso somente os primeiros esboços da futura Doutrina Monroe - que considerava "qualquer tentativa [dos poderes europeus] de estender o seu sistema a qualquer região [do hemisfério americano] como um desafio à paz e segurança [dos Estados Unidos]', - é preciso entender os laços importantes criados entre: os viajantes norte-americanos, a emergência de uma esfera pública nos Estados Unidos, e a nova monarquia nos trópicos.

Este artigo tenta explorar as notícias da chegada da corte portuguesa no Brasil através de uma leitura de sobrevôo de alguns jornais norte-americanos, terminando com as observações feitas por um viajante norte-americano sobre o Brasil e com os comentários à aclamação de um monarca nas Américas. Mas comecemos assim como Hipólito da Costa fez quando chegou à Filadélfia: adentrando pelas páginas dos jornais norte-americanos, nos quais as notícias sobre a chegada do príncipe regente Dom João foram tratadas com curiosidade, uma certa ambigüidade e, por incrível que pareça, poesia. 


\section{"UM NOVO EVENTO NA HISTÓRIA DA AMÉRICA"}

A primeira menção nos periódicos norte-americanos de um projeto que visava a transferir a corte de Lisboa para o Brasil encontra-se na Federal Gazette and Baltimore Daily Advertiser (um jornal comercial publicado entre 1796 e 1825) no final de agosto de 1801. Nos últimos dias da chamada Guerra das Laranjas, na qual Portugal se viu obrigado a capitular diante das superiores forças espanholas, uma carta escrita de Lisboa revelava as possíveis condições às quais Portugal estaria sujeito com o fim da guerra, inclusive a perpétua dependência de Portugal vis-à-vis a Espanha, o pagamento de uma taxa altíssima aos franceses, e a navegação livre dos franceses pelos portos do Brasil e pelo Rio Amazonas. Dadas essas condições, e para explicar um boato que já circulava sobre a possibilidade de o príncipe regente ficar preso em Madri, o jornal americano explicava que "a humilhação e duro tratamento que [o príncipe regente] provavelmente experimentará é capaz de induzi-lo a tomar uma providência que a boa razão já se lhe prescrevia"4. Essa providência foi a fuga ao Brasil. Essa mudança da sede da monarquia, segundo o jornal, poderia converter um príncipe fraco num verdadeiro imperador: "Porque apesar de ser o príncipe mais débil da Europa, é possível que ele chegue a ser o soberano do mais poderoso e florescente império do mundo, desde que tirasse proveito dos problemas surgidos nessa parte do globo, e se transportasse à América"s.

A possibilidade da fuga do príncipe regente ao Brasil suscitou múltiplas reações na Europa nesse período, e os jornais americanos seguiram essas opiniões através de canais mercantis e culturais em Londres, nos Países Baixos, e na própria metrópole portuguesa. A Gazette of the United States, um braço não-oficial do governo naépoca de George Washington e partidária dos chamados "Federalistas", chegou a publicar uma carta escrita por um comerciante de Rotter- dam, em que se elogiava a "determinação do Príncipe do Brasil a procurar refúgio nos seus domínios Americanos... [o que] revela a máxima honra do seu espírito e da sua magnanimidade"6. Ao mesmo tempo, esse jornal parecia vacilar sobre a importância da luta armada para reconquistar um território invadido. Em alguns casos, esse holandês dizia que a "prudência de uma fuga na hora certa" valia mais do que um patriotismo cego. Em outros, porém, esse correspondente enfatizava que era imprescindível aos patriotas contestarem e desafiarem os invasores, "mesmo se ficassem sepultados nos escombros das suas próprias cidades" 7 . Aluta armada para expulsar um exército invasor foi, obviamente, um elemento-chave na Independência norte-americana, e não surpreende que essa estratégia fosse bem vista por um órgão que se aliava ao partido de George Washington, grande herói dessas mesmas guerras de Independência.

Se a idéia de uma fuga da corte ao Brasil aparece nessa carta escrita por um mercador holandês como um acontecimento provável, ou pelo menos um ato plausível, outras notícias em números posteriores dos jornais norte-americanos oscilariam marcadamente entre as duas possibilidades. No dia 3 de novembro de 1803 , ao dar notícia de um pacote de cartas escritas em Lisboa pelo duque de Cumberland, a Kennebec Gazette do Maine sublinhava que "em nenhuma das cartas há menção de que o Príncipe do Brasil esteja se preparando para uma ida com a corte às suas possessões na América do Sul, como foi recentemente proclamado"8. Com a Inglaterra diretamente envolvida na operação naval que transferiria a corte da Europa para as Américas, não é de estranhar que o duque de Cumberland não tenha falado sobre o assunto. Porém, duas semanas depois, na Reporter de Vermont, lêem-se notícias exatamente contrárias: “O Príncipe dos Brasis está sem a maior dúvida preparando a sua frota, resolvido a deixar a Europa em direção às suas colônias na América do Sul"'. Outros jornais apresentavam as duas possibilidades sob a mesma manchete. Na matéria intitulada "Notícias Estrangeiras" do Western Star, publicada
$4 \begin{aligned} & \text { Federal Gazette and Baltimore } \\ & \text { Daily Advertiser, Baltimore, } 31 \\ & \text { de agosto de 1801, p. } 3 .\end{aligned}$
5 Idem, ibidem.
6 Gazette of the United States, 27
de outubro de 1803, p. 3.
7 Idem, ibidem.
8 Kennebec Gazette, Augusta,
Maine, 3 de novembro de
1803, p. 3.
9 Reporter, Brattleboro, Vermont,
14 denovembro de 1803, p. 2. 
em outubro de 1806, lêem-se dois artigos lado a lado que descrevem a situação do navio britânico Hibernia. O primeiro artigo notava que o navio estava "preparado para uma longa viagem que levará o Príncipe Regente de Portugal aos Brasis, para estabelecê-lo como Rei [naquela parte das Américas]"; enquanto o segundo explicava que esse mesmo navio "seguirá até Lisboa, mas é difícil cogitar que o propósito será aquele mencionado há um ou dois dias, que era o de receber a bordo o Príncipe do Brasil" ${ }^{10}$. E ainda outros jornais falaram das dificuldades que a corte portuguesa ia encontrar ao empreender esse tipo de viagem: "É opinião de muitas pessoas que as dificuldades que se apresentam à possível emigração da corte são de tal proporção que a sua realização seria impossível" ${ }^{11}$. Essa profusão de prognósticos se deve em parte às várias fontes utilizadas pelos periódicos norte-americanos, a maior parte deles dependente dos correspondentes em Londres e outros locais da Europa. Mostra também os enormes problemas técnicos enfrentados pela corte. Mas revela, sobretudo, a maneira ambígua como essa conjuntura foi vista pelos norte-americanos, por um lado sujeitos a certa defasagem na comunicação das notícias, e por outro demonstrando uma razoável desconfiança na veracidade das fontes.

Já próximo à saída da corte no dia 29 de novembro de 1807, alguns jornais começaram a explicar de forma histórica o motivo por trás desse ato político sui generis: “A transferência [translation] da sede do governo português de Lisboa para o Brasil foi contemplada pela primeira vez sob a administração do marquês de Pombal”, explicou um artigo da Aurora, dando a entender que era a única maneira possível de preservar o Brasil. Mais tarde, como logo veremos, a singularidade da transferência da corte serviria de fato para aumentar a curiosidade pela história do Brasil, “um país que deve peculiarmente interessar ao mundo por ser a sede da Realeza e o refúgio de um Potentado europeu" ${ }^{12}$. Mas esse noticiário sobre a origem da idéia de sediar a monarquia portuguesa no Brasil logo cedeu lugar às

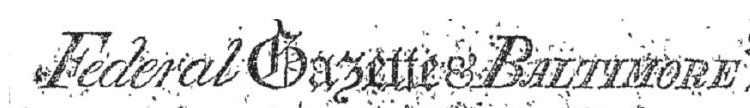
Seven Dóllars-per Annumi] . .
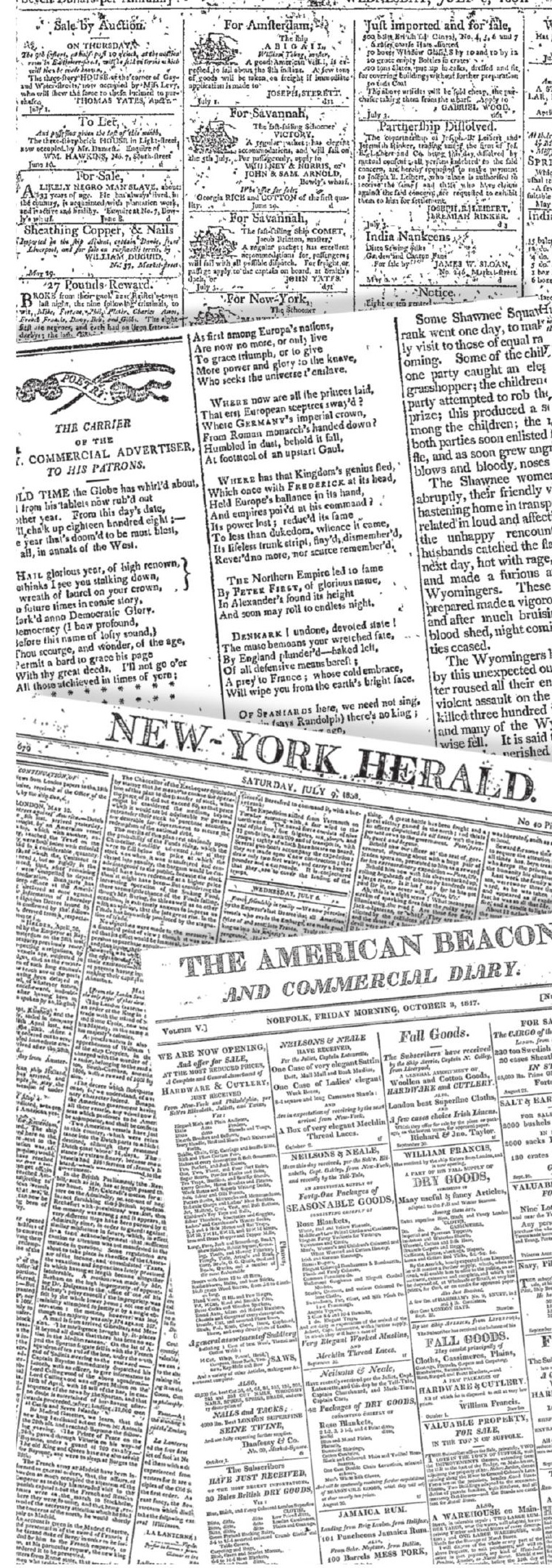
15 Adam Smith, A Riqueza das Nações, livro 4, capítulo 7 , parte 3 .

16 "Trade with the Brazils Opened", in New-York Herald, 9 de jutho de 1808.

17 Hampshire Federalist, 14 de janeiro de 1808 , p. 4 l"With pride shall sing posterity/ How Demos made us great and free"l.

18 Hampshire Federalist, 14 de janeiro de 1808, p. 4 l"Of Portugal, the powers among, / But little can be said or sung, / She'll bow to Bonaparte's will, / Or send her Princes to Brazil. In either case the kingdom's dead, /And never more will raise its head").

19 Washington Expositor, 2 de abril de 1808, p. 89/"Hesung, how George's loyal government/ The court of Portugal to Brazil sent; / Whither, if things with him no better grow, / Perchance his majesty may migrate too; / Giving to vile Columbia's vulgar brood/Approximation to the royal blood: / And a courtlyatmosphere, / Byawhole continent, indeed, too near"). do nível - das primeiras descobertas da América, aquilo que Adam Smith declarou (junto com a descoberta da passagem às Índias orientais) serem “os maiores e mais importantes eventos gravados na história da humanidade"15.

Smith fez esse comentário numa seção da sua obra-prima chamada "Das Vantagens que a Europa Extraiu da Descoberta da América," e não é por acaso que o jornalista da Essex Register colocou esse acontecimento em condição igual às descobertas portuguesas. Para os Estados Unidos, a chegada da corte teve uma importância ímpar graças à abertura dos portos e ao fim das restrições comerciais entre as duas partes do hemisfério. Por causa da relevância dessa notícia para a comunidade mercantil de Nova York, o New York Herald publicou o decreto integral de Dom João declarando a abertura do comércio entre os dois continentes. As possibilidades comerciais criadas pela proclamação do príncipe regente levaram esse mesmo jornal a especular sobre os benefícios potenciais que os Estados Unidos poderiam atrair do novo arranjo geopolítico: "Se os habitantes daquele imenso e rico país pudessem se prover dos suprimentos mais básicos e menos valiosos do nosso solo setentrional, [...] eles não seriam obrigados a gastar o seu trabalho com as necessidades de vida. Em vez disso, poderiam cultivar o anil, açúcar, café, cacau, algodão, etc."16. A listagem desses produtos mostra bem o que estava em jogo para os Estados Unidos na esfera comercial, e as mudanças regionais que a chegada da corte poria em vigor para aqueles países ao norte do Equador.

Mas o entusiasmo com a instalação de uma corte européia nas Américas não ficaria somente no âmbito histórico e comercial. O evento ganhou novas formas de tratamento que ultrapassaram os gêneros literários tradicionais, como se pode ver evidenciado em vários poemas escritos, recitados e eventualmente publicados nos jornais americanos. Nesses jornais, a realeza portuguesa apareceu como um parente anômalo dentro de uma família de monarcas em via de extinção. Prognosticando sobre os acontecimentos previstos para o ano seguinte, o editor do New York Commercial Advertiser deu aos seus clientes uma lição histórica sobre a queda das monarquias européias, e escolheu uma forma poética para o fazer. Sob uma linda ilustração que mostrava uma pluma e a palavra "poesia", o autor desse poema explicou que "com orgulho a posteridade cantará/ a maneira em que Demos nos liberou" ${ }^{17}$, enfatizando as raízes democráticas dos Estados Unidos em contraste com as tradições despóticas das monarquias na Europa. Portugal, nesse contexto, foi representado como um reino morto, devido em parte à decisão de mandar o seu príncipe ao Brasil:

"Entre os poderes, pouco se pode

Dizer e cantar de Portugal,

Ou perderá a Bonaparte,

Ou enviará seus príncipes ao Brasil;

Em todo caso, o reino morre

E nunca mais levantará sua cabeça" ${ }^{18}$.

Um mês depois, uma ode foi lida na Columbian Reading Society de Washington tratando do embargo posto em prática pelo presidente Thomas Jefferson. Em reação ao recrutamento de soldados da marinha americana para o serviço nas armadas inglesas, o ato visava a uma parada completa de saídas dos barcos americanos, uma postura que o próprio Jefferson viu como a melhor alternativa para não entrar em guerra. Utilizando a popular melodia de "Yankee Doodle Dandy", o autor dessa ode fez uma brincadeira referindo-se aos eventuais efeitos do embargo, ao invocar a ida da família real ao Brasil para satirizar o monarca inglês:

"Ele cantou, como o leal governo do [rei] [George

Mandou a corte portuguesa ao Brasil;

Se as coisas não ficarem melhores para ele, Talvez [George] migre também;

Dando à vulgar família da Colúmbia

Aproximação ao sangue real;

E uma atmosfera cortesã

Por um continente inteiro, de fato, perto [demais"19. 
A possibilidade de o rei George vir às Américas obviamente estava longe da realidade. Mas o perigo de uma "atmosfera cortesã" chegando ao hemisfério americano já nesse poema criava um certo mal-estar. Essa sensação antimonárquica nos Estados Unidos só cresceria durante a década que separou a saída da corte portuguesa de Lisboa e a notícia de que um monarca tinha sido aclamado no hemisfério reservado, na ótica norte-americana, a Demos e os seus seguidores.

\section{"UM LUGAR ONDE OS DEUSES PODERIAM HABITAR, OU PEREGRINAR COM DELEITE"}

A partir de outubro de 1817, os leitores dos jornais norte-americanos começaram a receber notícias de uma missão especial enviada pelo executivo dos Estados Unidos para alguns países da América do Sul, uma expedição "cujos propósitos", segundo o American Beacon and Commercial Diary de Norfolk (Virgínia), "têm sido presumidos mais do que amplamente explicitados" ${ }^{20}$. Segundo o relato oficial da expedição, porém, a missão foi enviada para que os "nossos preconceitos sejam dissipados, e o nosso conhecimento aumentado, sobre os países onde recentemente têm acontecido as mais interessantes mudanças políticas, e com os quais a nossa interação, por causa [dessas mudanças], poderá no futuro ser extensa e benéfica [para nós]"21.

As colônias sul-americanas tinham ganho um lugar de destaque na política do jovem país norte-americano com a publicação de um panfleto escrito por um jovem advogado chamado Henry Marie Brackenridge, endereçado ao então presidente James Monroe e intitulado South America: a Letter on the Present State of that Country. Num texto de 50 páginas, em que descreveu a importância geopolítica da América do Sul, ele tentava suprir uma ausência de informação e uma falta de interesse da parte dos norte- americanos, reclamando que "pessoas que possuem um minucioso conhecimento dos diversos países da Europa ainda não fizeram o esforço de conhecer ao menos os esboços geográficos deste nosso grande continente meridional"22. Para Brackenridge, a geografia era um assunto essencial. No panfleto, ele explicou que a distância entre a Europa e as Américas "impediu que [as colônias americanas] se tornassem dependentes... dos pequenos estados europeus" 23 . Por esse motivo, continua Brackenridge, “o rei dos Brasis agiu de forma sábia ao transportar a sua corte e governo a esta sua possessão americana, convertendo assim a antiga sede do império numa província”. Apesar do fato de que, segundo Brackenridge, teria sido preferível que a forma monárquica não fosse escolhida para governar esse novo território, ainda assim era melhor não manter o Brasil como colônia. Ele até sugere que teria sido melhor se o próprio George III tivesse "transferido a sua coroa da Ilha da Grã-Bretanha ao continente americano", o que o tornaria "senhor do novo mundo" criando uma situação na qual ele poderia ter mantido as suas possessões americanas. Além dessas observações políticas, Brackenridge sublinhou que os norte-americanos não tinham informações suficientemente claras sobre a América do Sul. "As idéias confusas que temos do interior da América do Sul”, ele comentou, "nos levam a erros de opinião das mais estranhas formas" 24 . Essa carta, e sobretudo a delicada situação política no Rio da Prata, parece ter motivado o presidente Monroe a enviar uma missão especial à região. Num discurso oficial ao Congresso, o presidente Monroe explicou o propósito da missão: “Obter informações sobre qualquer assunto que interessasse aos Estados Unidos; inspirar sentimentos em todas as autoridades, de ambos os lados, de que a nossa disposição seja amigável [...] com uma neutralidade imparcial; e assegurar o devido respeito para com o nosso comércio em cada porto, e de toda bandeira"25. Não é de surpreender que Henry Marie Brackenridge foi incluído como um dos enviados especiais.
20 American Beacon and Commercial Diary, Norfolk, Virginia, 3 de outubro de 1817, p. 3

21 Rodney Caesar Graham, Reports on the Present State of the United Provinces of South America l"[...] our prejudices should be dispelled, and our knowledge enlarged, regarding countries where the most interesting political changes have recently taken place, and with which our intercourse by these changes may in future become so extensive and so beneficial").

22 Henry Marie Brackenridge, South America: a Letter on the Present State of that Country, to James Monroe, President of the United States, Washington, D.C., Office of the National Register, 1817, p. viii.

23 Idem, ibidem, pp. 12-3

24 ldem, ibidem, p. 29

25 "Discurso do Presidente dos Estados Unidos ao Congresso", citado em: Brackenridge, Voyage to South America, Performed by Order of the American Government in the Years 1817 and 1818 , in the Frigate Congress, London, J. Miller, 1820, p. 78 
A missão que saiu do porto de Norfolk a bordo da fragata Congress no dia 3 de dezembro de 1817 foi constituída por três comissários: Caesar Augustus Rodney, John Grahame Theodorick Bland. Rodney era o membro mais preeminente do grupo, tendo servido como representante no Congresso dos Estados Unidos entre 1802 e 1804, e como procurador dos Estados Unidos entre 1807 e 1811 . Aliado de Jefferson, ele seria nomeado primeiro-ministro plenipotenciário dos Estados Unidos na jovem República Argentina no final da sua carreira. Graham, que serviu na embaixada americana em Madri entre 1801 e 1803, foi o único que tinha experiência prévia como diplomata. Os motivos da participação de Theodorick Bland eram menos explícitos, pois ele não tinha nenhuma experiência relevante para essa missão, apenas suas relações um pouco obscuras com um grupo de propagandistas de Baltimore, que eram favoráveis aos revolucionários de Buenos Aires, e com os quais ele podia ter tido algum envolvimento financeiro ${ }^{26}$. Junto a esses três comissários participaram o secretário da comissão - Brackenridge - e um cirurgião e botânico, William Baldwin, natural da Pensilvânia, que teve uma formação inicial com o naturalista Moses Marshall e o médico Benjamin Smith Barton, ambos da Pensilvânia. Baldwin manteve também uma correspondência profícua com o botânico Henry Muhlenberg, que durou até a sua morte em 1815 , e outra correspondência ainda com seu amigo William Darlington, para quem escreveu freqüentemente durante o período que nos interessa aqui - a sua estadia na América do Sul.

O navio Congress viajou durante quase

26 Wayne D. Rasmussen, "Diplomats and Plant Collectors: the South American Commission, 1817-1818", in Agricultural History 29.1, 1955, pp. 23-

27 Brackenridge, Voyage to South America, op. cit., p. 90

28 Idem, ibidem, pp. 96-7

29 ldem, ibidem, p. 94.

30 Idem, ibidem, p. 124

31 Idem, ibidem, p. 125 dois meses, avistando o Pão de Açúcar no dia 28 de janeiro de 1818. Ao chegar à Baía de Guanabara, e ao descrevê-la depois, Brackenridge ficou maravilhado com a paisagem da capital, uma reação típica de estrangeiros chegando ao Rio de Janeiro pela primeira vez. Brackenridge se referiu à "magnífica cena [que] se abriu diante de nós", o porto figurando como "uma bacia [que] se expandia de uma ma- neira majestosa, confinada por montanhas altas e florestadas, [e] intercalada com precipícios e picos pedregosos"27. Diante dessa cena natural, a atmosfera social da capital lhe deixou com uma sensação bem menos agradável. Ele chamou a atenção à presença de vários "pretos barulhentos" ("noisy negrões") que aguardavam numa fila para beber água de uma fonte na cidade. Brackenridge ficou impressionado sobretudo pelo sofrimento desse canto de escravos, cuja dor eles tentavam superar ao fazer "uma espécie de barulho agudo, não dessemelhante de um grupo de gansos selvagens" 28 .

Mesmo escutandoo pranto dos escravos, a sensação mais aguda que ele sentiu foi a de um republicano em terras de despotismo, uma rejeição ao monarquismo que o levou a ficar surpreso com a recepção aberta e honrosa que receberam do próprio monarca: "A circunstância de sermos uma república solitária, e por isso uma contínua e tácita censura de monarquia, talvez nos induza a acreditar que os reis não podem agir de uma forma cordial conosco"29. De fato, e aparentemente por coincidência, a fragata Congress chegou ao Rio de Janeiro uma semana antes do maior evento político no hemisfério desde a chegada da corte: a aclamação do príncipe regente. Apesar de não ter sido convidado para a cerimônia, Brackenridge descreveu com admiração a "ingenuidade mostrada no arranjo das iluminações [fogos de artifício]”, e a apresentação dos navios "iluminados da maneira mais curiosa e com melhor gosto"30. Mas depois de dois dias de escutar os barulhos e enxergar os fogos de artifício, Brackenridge e sua companhia não conseguiram se sentir bem com essa "espantosa e maravilhosa manifestação" em homenagem ao novo rei aclamado no Brasil. Ele fez uma comparação entre a "cerimônia simples e não-afetada" para instalar o presidente dos Estados Unidos e os "barulhos e brilhos calculados para intoxicar, maravilhar e estupidificar [intoxicate, astound, and stupify]'. Segundo Brackenridge, "o verdadeiro entusiasmo de um homem livre não precisa da ajuda desses elementos" 31 . 


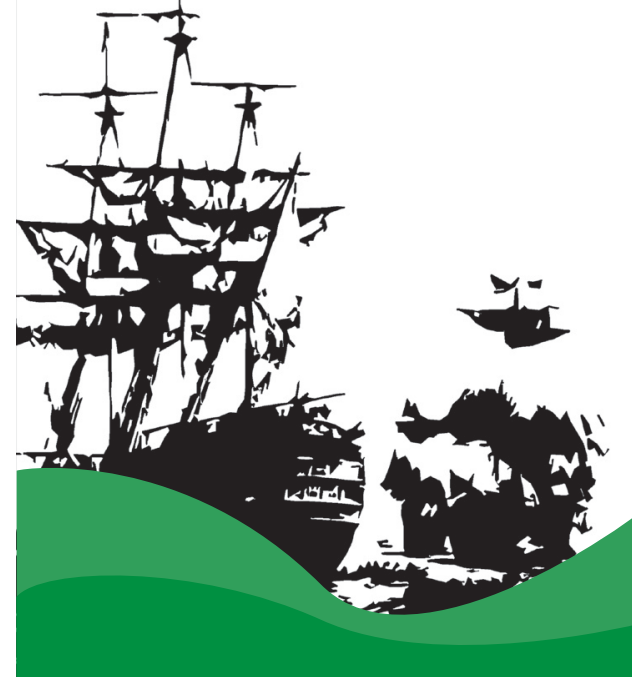

Esse incômodo com a monarquia e seus seguidores não o impediu, porém, de refletir sobre os destinos entrelaçados dos Estados Unidos e do Brasil, uma comparação que ele insistiu seria cada vez mais necessária com a passagem do tempo. “Talvez pareça prematuro comparar os Brasis com o nosso país", Brackenridge escreveu: "mas chegará o momento em que tal comparação parecerá natural, e mesmo inevitável"32. A comparação, segundo ele, dependia do resultado das guerras de independência na América espanhola e se elas acabariam ou não numa "anarquia" política. "Não é o caso com os Brasis", refletiu Brackenridge. "[O Brasil] é um e indivisível, e é provável que fique assim... Por isso, quando consideramos os vastos recursos e capacidades do Brasil, não é coisa visionária de dizer que esse império é destinado a ser o nosso rival" 33 .

Nas últimas páginas em que descreve a passagem da sua comitiva pelo Rio de Janeiro, Brackenridge especula sobre uma situação hipotética: qual seria a reação de um norte-americano chegando pela primeira vez ao Brasil, uma pessoa "habituada a uma liberdade aparentemente sem controle", ao se deparar com as terras americanas do rei português ${ }^{34}$. Brackenridge fecha essas observações com uma série de questões retóricas fazendo uma comparação explícita entre as condições físicas e geográficas do Brasil e as atitudes culturais do seu povo, sobretudo aquelas que estavam relacionadas com a possibilidade - até aquele momento, remota-de um regime de democracia que surgiria naquela parte da América do Sul:
"Essa questão me veio à mente: qual seria a diferença no nosso caráter e na nossa condição se o nosso destino nos tivesse colocado neste país em vez daquele que possuímos? Teriam então os germes da liberdade fincado raízes neste solo, como floresceram num clima mais rigoroso, onde a necessidade impeliu para uma vida mais laboriosa e empreendedora? Teriam esses princípios da liberdade, maturados por séculos e levados pelos colonos, murchado quando transplantados neste solo fértil, sob o calor do sol? Ou teria essa nossa tão prezada liberdade perdido seu domínio num país onde os rios correm pelos leitos de diamantes e areias de ouro?"35.

Essas reflexões sobre o destino dos impérios modernos e suas colônias emergem de uma visão hemisférica: entre norte e sul, entre os Estados Unidos e o Brasil. Não se trata da velha discussão de Montesquieu e Hume sobre a influência do clima no caráter das pessoas, pois Brackenridge escreve claramente na Voyage to South America que "os poderes [do ser humano] são capazes de ser exercidos tanto na zona tórrida quanto nos climas mais vigorosos"36. Essa observação filosófica emerge da experiência vivida de um americano nascido nos Estados Unidos visitando um país que ele percebe como aliado e rival ao mesmo tempo. "Como um americano", Brackenridge reflete, "não posso sentir nada além de orgulho ao vislumbrar os destinos celestes deste novo mundo", citando em seguida uma estrofe do Paraíso Perdido de Milton, em que o autor inglês descreve a terra como um "Um lugar onde os deuses poderiam habitar, ou peregrinar com deleite" ${ }^{37}$. Apesar do estabelecimento de uma nova monarquia no novo mundo, Brackenridge não deixa de sentir uma aliança com esse poder emergente no hemisfério, um país que, segundo um artigo do New York Spectator, publicado no dia 25 de maio de 1808 , “é capaz de se tornar, com a passagem do tempo, se não a primeira, então a segunda maior nação das Américas"38.
32 ldem, ibidem, p. 129.

33 ldem, ibidem, p. 129.

34 Idem, ibidem, p. 150.

35 ldem, ibidem, p. 151 I"This question has suggested itself to me, what difference would have been made in our character and condifion, had it been our fortune to have been placed in this country, instead of the one which we possess? Would the germs of liberty have taken root in this soil, and flourished as they have done in a more rigid climate, where necessity urged to a more laborious and enterprising life? Would those principles of liberty, carried with them by the colonists from a stock which had been maturing for ages, have withered when transplanted into this fertile soil, and under this warm sun? Or would that liberty which is so much prized, have lost her dominion in a country, whose rivers flow over beds of diamonds, and whose sands are gold?").

36 ldem, ibidem, p. 136.

37 John Milton, Paradise Lost, livro 7, estrofes 329-30.

38 New York Spectator, 25 de maio de 1808, p. 1 